\title{
SEPARATION AND ${ }^{14} \mathrm{C}$ DATING OF PURE POLLEN FROM LAKE SEDIMENTS: NANOFOSSIL AMS DATING
}

\author{
AUSTIN LONG, OWEN K. DAVIS and JEANNE DE LANOIS ${ }^{1}$
}

Department of Geosciences, The University of Arizona, Tucson, Arizona 85721 USA

\begin{abstract}
We have developed and tested a practical device for manually separating pollen from pollen concentrates in sufficient quantity for AMS ${ }^{14} \mathrm{C}$ dating. It is a combination of standard, commercially available equipment handled in a clean room by an individual trained to recognize pollen. A typical example requires about $15-20 \mathrm{~h}$ of hand-picking under the microscope. We show the usefulness of this procedure with results on a mid-Holocene segment from a core from Mono Lake. Sediments from this hardwater lake contain pollen and finely disseminated organic matter, but no macrofossils. The pollen dated $c a .1000 \mathrm{yr}$ younger than the bulk sediment. The sediment "date" is most likely affected by incorporation of limestone-derived carbon, and is erroneously old.
\end{abstract}

\section{INTRODUCTION}

The long-standing problem with ${ }^{14} \mathrm{C}$ dating of lake sediments is that events of interest, such as sedimentological and botanical changes, may not have the same apparent ${ }^{14} \mathrm{C}$ age as the bulk organic carbon fraction most often dated. Common reasons for this difference include: 1) carbon in the organic fraction derived from old groundwater or dissolution of limestone (the "hard water" effect, which yields ${ }^{14} \mathrm{C}$ dates older than correct age); 2) atmospheric carbon incorporated through fungal growth, which yields ${ }^{14} \mathrm{C}$ dates younger than correct age. Most ${ }^{14} \mathrm{C}$ dating of lake sediments occurs with analysis of terrestrial pollen, with the goal of inferring times of botanical changes. The most direct approach to ${ }^{14} \mathrm{C}$ dating these changes is by direct dating of terrestrial plant fossils. In many instances, pollen is the most abundant plant fossil adequately preserved. As typical pollen grains range from 0.01 to $0.2 \times 10^{-6} \mathrm{~g}$, at least $10^{2}$ to $10^{3}$ grains (depending on species) are required for an acceptable AMS ${ }^{14} \mathrm{C}$ date. Previous work (Brown et al. 1989) employed chemical and physical concentration procedures. Although a clear improvement, their pollen enrichments still contained chemically resistant non-pollen organic material, such as algal bodies, whose carbon derives from water rather than from the atmosphere. As AMS technology has decreased the amount of carbon necessary for dating without compromising precision, analysis of 100-200 $\mu \mathrm{g}$ samples has become possible. Thus, we have begun testing the practicality of manual pollen isolation.

\section{APPARATUS AND PROCEDURES}

We selected sediments at $200-215 \mathrm{~cm}$ depth at Mono Lake, California (Davis \& Kailey 1990). This core interval contained anomalously high pine percentages and low sagebrush percentages, above a layer barren of pollen. Davis and Kailey (1990) attribute this layer to the obliteration of local vegetation by a volcanic eruption. However, the demise of local vegetation might also have resulted from a very high lake level, such as the Dechambeau Ranch High Stand (3679 \pm 188 BP; Stine 1990). Mono Lake is isolated, and is fed by springs and runoff that contain terrestrial carbon. Hence, organic carbon from the lake dates $c a .1000$ yr too old (Broecker \& Walton, 1959).

The pollen in a 320 -g sample from $200-215 \mathrm{~cm}$ was concentrated by acid digestion and screening (cf. Brown et al. 1989). Carbonates and silicates were removed with concentrated $\mathrm{HCl}$ and $\mathrm{HF}$, cellulose and related compounds were removed by acetolysis, and humates were removed with 5\%

\footnotetext{
${ }^{1}$ Present address: Office of Contract Archaeology, University of New Mexico, Albuquerque, New Mexico 87131 USA
} 

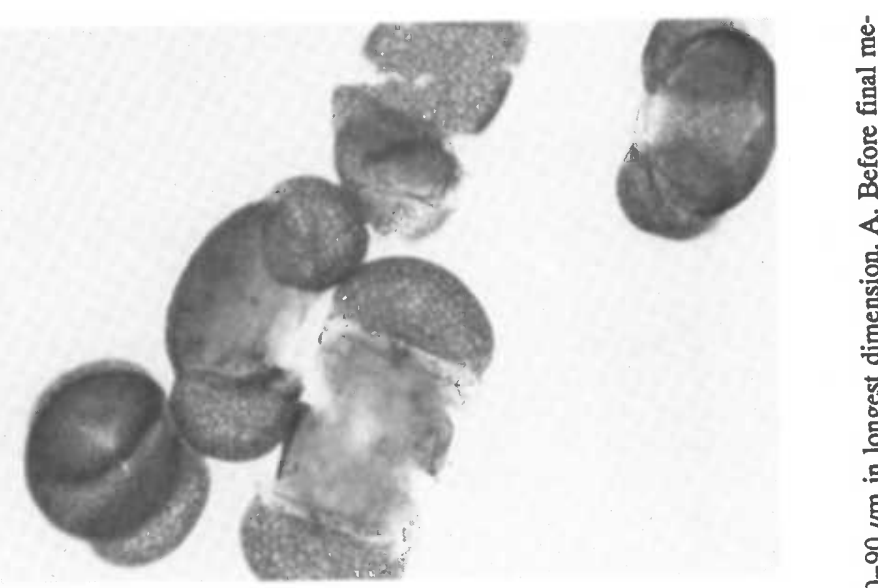

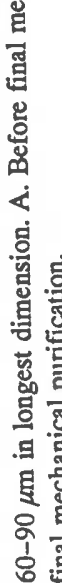

灵先

?

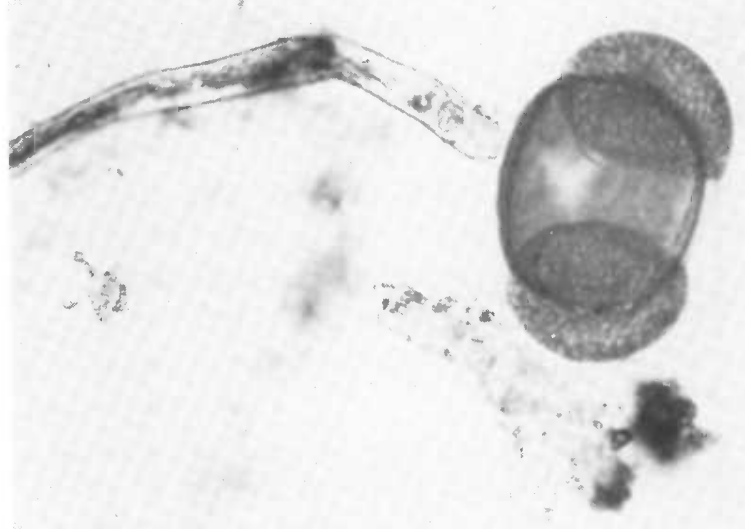

莺

最奠

응

1

음

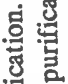

实

륨

娄

递

䨔

品

可

递

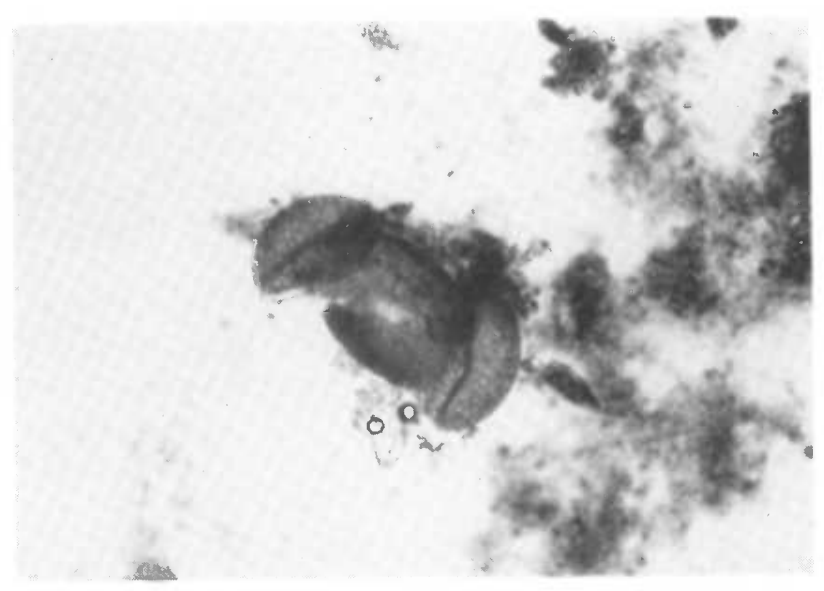

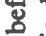

营

ㅎํㅇ

능

을 8

.

言

क

量学

尊.

.

븡

量雪

ㄱ.

올 둉 
$\mathrm{KOH}$. Each step was followed by repeated washing with deionized water, so soluble organic compounds also were removed. The pollen-rich residue was then filtered. The $>84-\mu \mathrm{m}$ fraction contained charcoal and plant and animal matter, the $<63-\mu \mathrm{m}$ fraction contained non-conifer pollen and colloidal material, and the $84-63 \mu \mathrm{m}$ fraction was nearly pure pine (99\%) and fir (1\%) pollen. All non-pollen material was mechanically removed. A date for the $200-215 \mathrm{~cm}$ interval was obtained for the core bulk sediment $(4605 \pm 60 \mathrm{BP}$; A-6267).

The apparatus for the manual pollen purification consists of a dissecting microscope (Nikon SMZ$2 \mathrm{~T}$ ) with a $2 \times$ objective adapter, and a special mechanical stage. The pollen-rich residue is placed on the mechanical stage in a petri dish. The microscopic contaminants then are sucked into a glass "needle" fabricated by heating and stretching a capillary tube. The needle is controlled by a micromanipulator (Narishige MO 155) with a "joystick." Under $90 \times$ magnification, the hollow tip of the needle (inner diameter $c a .200 \mu \mathrm{m}$ ) is positioned next to the non-pollen material using the joystick, and suction is applied with a stationary microsyringe (Narishige $1 \mathrm{H} 5 \mathrm{~B}$ ). The chemical extraction, screening and mechanical purification were done in the University of Arizona Palynology laboratory with $10 \mu \mathrm{m}$-filtered air. Figure 1 consists of three photomicrographs which illustrate the pollen extract before (A, B) and after (C) mechanical purification. Note the presence of organic matter and plant parts present before final purification.

The sample was centrifuged, excess water was decanted, and the sample was dried over silica gel. Then, $500 \mu \mathrm{g}$ of pollen were combusted in a sealed tube with $\mathrm{CuO}$, and the $\mathrm{CO}_{2}$ was reduced to graphite (Slota et al. 1987) for AMS dating (Donahue, Jull \& Zabel 1986). In cases of minimal amounts of pollen, a slurry of purified pollen can be pipetted directly into the combustion tube, frozen and the water sublimed. The ${ }^{14} \mathrm{C}$ date on pure pine and fir pollen is $3730 \pm 60 \mathrm{BP}$ (AA6837 ); this date is 875 yr younger than the bulk sediment result, but contemporaneous with the Mono Lake high stand (Stine 1990).

\section{DISCUSSION AND CONCLUSIONS}

We have developed procedures of physically removing non-pollen contaminants from pollen concentrates, using a micromanipulator under a dissecting microscope in a clean-room environment. The procedure requires less labor than we expected. One person can produce 2 to 3 samples of pure pollen in one week. The additional labor cost of manual purification ( $\$ 100-\$ 200$ per sample) is less than the cost of one AMS ${ }^{14} \mathrm{C}$ analysis. The procedure greatly reduces the uncertainty in the interpretation of the result. In the example from Mono Lake, the bulk sediment date is, most likely, too old due to the "hard-water" effect. Lakes situated in limestone terrains receive bicarbonate derived partly from limestone dissolution. If this bicarbonate does not equilibrate with atmospheric $\mathrm{CO}_{2}$ before aquatic plants growing in the lake utilize the bicarbonate as a source of carbon, the living plants will have a ${ }^{14} \mathrm{C}$ content between that of the limestone and the atmosphere, and consequently have an "apparent ${ }^{14} \mathrm{C}$ age." Organic matter from the remains of aquatic plants and organisms feeding on aquatic plants becomes part of the lake sediment. Macrofossils, such as wood fragments, pine cones and charcoal are often not present in core material in sufficient abundance for AMS dating, but pollen, a nanofossil, is usually present in suitable quantity. Thus, ${ }^{14} \mathrm{C}$ dating of pure pollen has the potential of being a valuable approach to assigning high-confidence dates to botanical changes observed from pollen analysis. 


\section{ACKNOWLEDGMENTS}

This research was supported in part by NSF grant BNS-8902140. Coring of Mono Lake was financially supported by the Los Angeles Department of Water and Power. NSF grant SES 9009974 provided funds for pollen extraction. We are also grateful for the help and cooperation of Lisa Park in the Geosciences Department, The University of Arizona, and of D. J. Donahue, A. J. T. Jull and L. J. Toolin in the Arizona-NSF AMS Facility.

\section{REFERENCES}

Broecker, W. S. and Walton, A. 1959 The geochemistry of ${ }^{14} \mathrm{C}$ in freshwater systems. Geochimica et Cosmochimica Acta 16: 15-38.

Brown, T. A., Nelson, D. E., Mathewes, R. W., Vogel, J. S. and Southon, J. R. 1989 Radiocarbon dating of pollen by accelerator mass spectrometry. Quaternary Research 32: 205-212.

Davis, O. K. and Kailey, J. 1990 Pollen analysis of a sediment core from Mono Lake, Mono County, California. Report to Brian White and Susan Rowgahni, Los Angeles Department of Water and Power.

Donahue, D. J., Jull, A. J. T. and Zabel, T. H. 1984
Results of radioisotope measurements at the National Science Foundation/University of Arizona tandem accelerator mass spectrometer facility. Nuclear Instruments and Methods 219(B): 162-166.

Slota, P. J., Jr., Jull, A. J. T., Linick, T. W. and Toolin, L. J. 1987 Preparation of small samples for ${ }^{14} \mathrm{C}$ accelerator targets by catalytic reduction of $\mathrm{CO}$. Radiocarbon 29(2): 303-306.

Stine, S. 1990 Late Holocene fluctuations of Mono Lake, eastern California. Palaeogeography, Palaeoclimatology, Palaeoecology 578: 333-381. 